\title{
Innovative Approach for 3D Presentation of Plane Culturally- Historical Objects by Tactile Plates for Disadvantaged Users (low- sighted or visually impaired)
}

\author{
Dimitar Karastoyanov ${ }^{1, *}$, Nikolay Stoimenov ${ }^{1}$, Stanislav Gyoshev ${ }^{1}$ \\ ${ }^{1}$ Institute of Information and Communication Technologies, bl. 2, ac. G. Bonchev str.1113 Sofia, Bulgaria
}

\begin{abstract}
The presented paper aims to create a more affordable way to present culturally-historical objects like paintings, masterpieces, tapestries, objects, artifacts, etc., and make it more accessible to visually impaired or blind people. The State of the Art of the team shows that the already used method received good feedback at the exhibition "Battle of Pavia 1525" in Pavia, Italy, from more than 11000 people, who take part in exhibition in Italy. This encouraged the team to continue developing the idea. An approach on the base of the Bulgarian patent application named "Tactile graphical tile for visually impaired people" is described. By using innovative methods for 3D digitalization, also by using more accessible and affordable materials for 3D printing the culturallyhistorical objects can be presented in schools for visually impaired or blind people. By using approaches are shown how can be reduced the time for 3D digitalization. Conclusion and future developments are presented.
\end{abstract}

\section{Introduction}

Nowadays, a world surrounded by technics, computers, touchscreen phones, and tablets, complicates the integration of visually impaired or blind users, who are a large part of the society. For this reason, scientists are working hard on different ideas to help for better integration of those users. The Braille screens, terminals, scanners, printers that have been developed so far, contributed a lot and helped to visually impaired people, but they still have no idea about the graphics environment. Additive manufacturing is a great way to produce tactile tiles for visually impaired or blind users. By using a 3D printed tactile tiles, the blind user will get an idea of a complete image, figure, painting, etc. From paintings, masterpieces, images, icons, etc. can be produced tactile tiles. The tactile tiles represent elevated surfaces so that visually impaired people will be able to sense and "see" by using their fingers and hands.

The mentioned 3D printed tactile tiles method was already realized in one exhibition and a museum $[1,2]$. The exhibition was visited by 11,000 people in JuneNovember 2015 [1].

The goal is by using an innovative approach for $3 \mathrm{D}$ representation of plane culturally-historical objects by tactile plates to be given the opportunity to disadvantaged users (low-sighted or visually impaired) to explore this content.

\section{State of the Art}

So far, in Bulgaria, there is not much experience in 3D digitization of cultural and historical heritage, especially for disadvantaged people (visually impaired). The Institute of Information and Communication Technologies at Bulgarian Academy of Sciences (IICTBAS) has extensive experience and expertise in the application of computer technologies in various urban and cultural fields. In particular, within the framework of a large European project ACOMIN (Advanced Computing for Innovation), we took part in EXPO2015 Milan, Italy by preparing and conducting the exhibition "Battle of Pavia 1525". A book is written and published with co-authored by Pavia University, Computer Vision department, headed by Prof. Dr. Virginio Cantoni [1]. A number of articles, with the team headed by Professor Virginio Cantoni from Pavia University and team of Professor Dimitar Karastoyanov (IICT-BAS), Dr. Nikolay Stoimenov (IICT-BAS), Dr. Stanislav Gyoshev, Luca Lombardi and Alessandra Setti presents in the 16th International Conference on Computers Helping People with Special Needs (ICCHP 2018) [3, 4].

After the success of the team with an exhibition in Pavia, Italy and museum in Milan, Italy [2], the work continued developing and producing tactile tiles at a national level in Bulgaria. By using the techniques from previous works $[1,3,4]$, the team produced tactile tiles for visually impaired and blind people with famous paintings from Bulgarian history.

The tactile tile, which is standing next to the original painting in the museum is shown on fig. 1 . The white contours are extruded, and by them, the visually impaired people can "see" the painting. The white dots are the Braille alphabet symbols, and on the right is the legend for the symbols.

\footnotetext{
Corresponding author: dimikara@abv.bg
} 
One of the paintings represents the battle for rescuing the Samaritan flag (fig. 2), where a Russian Commander Kalitin (the person on the horse) holds the Samaritan flag, given to Bulgaria from Russian city Samara. When he takes the flag from the previous killed flag holder, a bullet from the Turkish army kills him. This battle takes down seven flag holders, but the flag is saved. One of the great historical facts of the Bulgarian army is that no one museum around the world can't show a Bulgarian flag. This is due to the fact that they never lost a flag on a battlefield during all the wars, they take part.

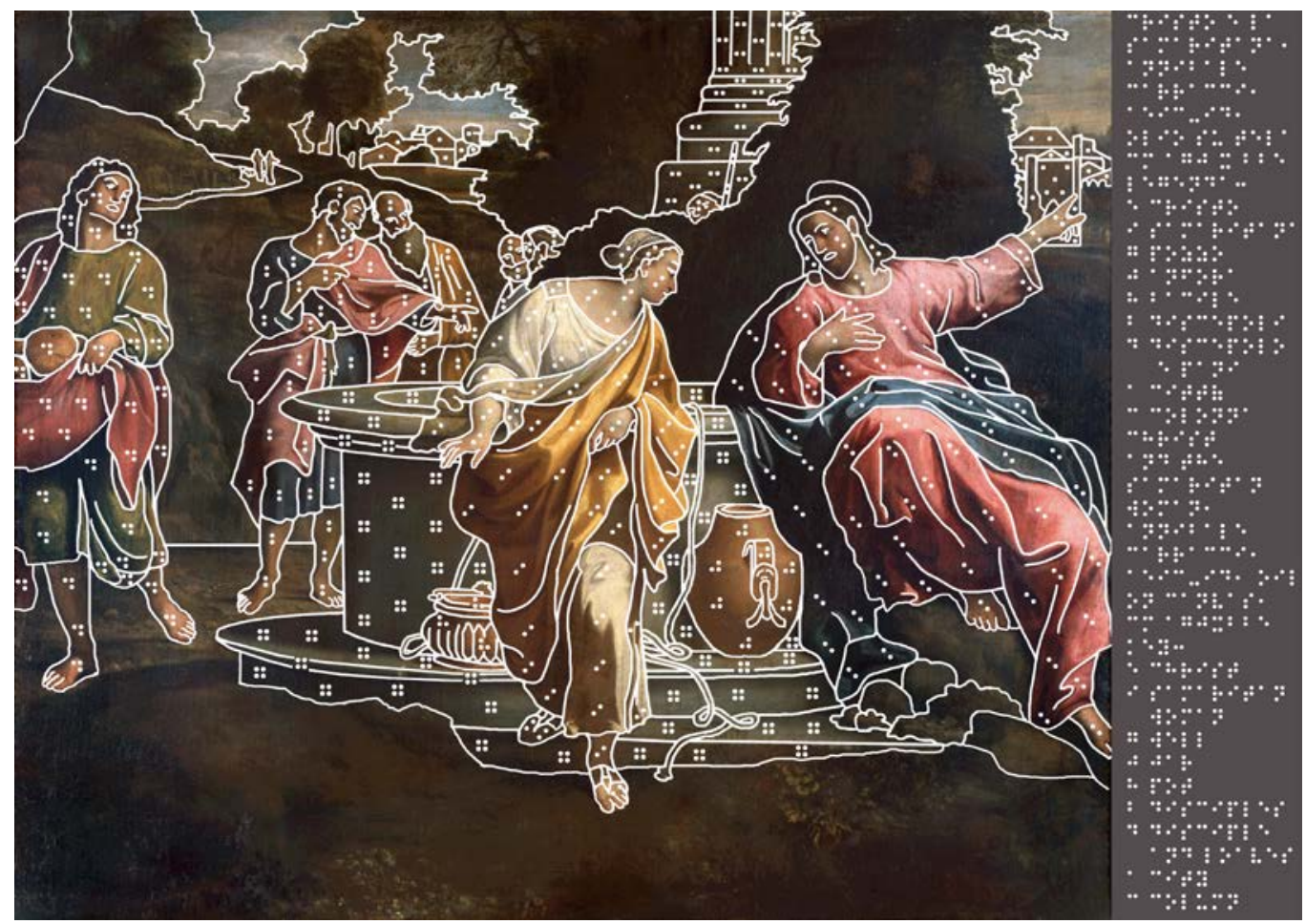

Fig. 1. Tactile tile for visually impaired people [2].

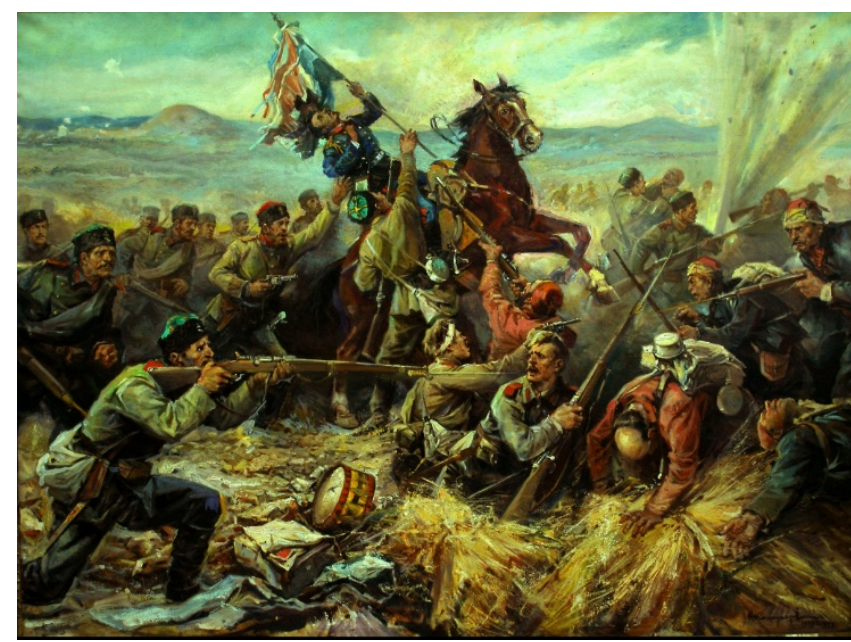

Fig. 2. Rescuing the Samaritan Flag [5].

\section{Digitalization Methods for 3D Presentation for Culturally-Historical Objects}

Before all tactile tiles were designed by following the principles in [1] and patent application [6]. All persons in the tactile tiles are segmented, contoured and extruded on two levels. The up level represents a filled figures with cut out contours for details in the figure for example fingers, nose, eyes, etc. The second level is only extruded contours of the selected figures with contoured and extruded details, again hands, eyes, clothes, etc.

The results and obtained data from the exhibition shows that the used method is working. One disadvantage is that the material for those tactile tiles is still very expensive and can be easily damaged.

Until now, the used method for digitalizing paintings and masterpieces was by selecting all figures and contours manually in software, by human and with a digital handwriting pad. After that, another software was used for extruding and making the tiles ready and compatible for $3 \mathrm{D}$ printing. For the $3 \mathrm{D}$ printing is used a full-color 3D printer.

An example is shown on fig. 3. On the figure position 1 is extruded figure, position 2 is a contoured figure, position 3 is a Braille annotation (for example $\mathrm{S}$ for Soldier), and position 4 is a legend with Braille alphabet. The described painting is placed in a museum in the city Stara Zagora, Bulgaria, where visually impaired or blind people can "see" it and explore it [7].

On fig. 4a is shown the method, used in the patent application [6]. The strong contour line presents extruded figures. The dashed line presents only contoured figures. The dots in the figures presents Braille annotations. The Braille annotation legend is shown on the bottom of the tactile tile in Bulgarian Braille, and it means: P-Samarian Flag, П-Commander Kalitin, K-Horse, O-Fighter, T- 
Turkish fighter, Б-Drum, B-Gun, Ч-Bag. When the figures alternates bold and contoured, it is more easily for the visually impaired users to make difference between them. For better understanding are presented the different stages of the figures - extruded level (fig. 4b) and contour level (fig. 4c).

The team plans to use new methods and means for faster and automated segmentation and contouring of the objects, which will decrease the required time for one painting or masterpiece.
Another used method for digitalization of culturallyhistorical objects, such as artifacts, treasures, etc. is a 3D Scanner HandyScan (fig. 5). The object is prepared for scanning after scanning is processed and prepared for 3D printing.

This method is very effective for extremely valuable treasures, who are strictly guarded, locked, and secured. Another advantage of the method is, that from those objects can be produced 3D copies and can be presented and touched from visually impaired people. This will give them the opportunity to get acquainted with them.

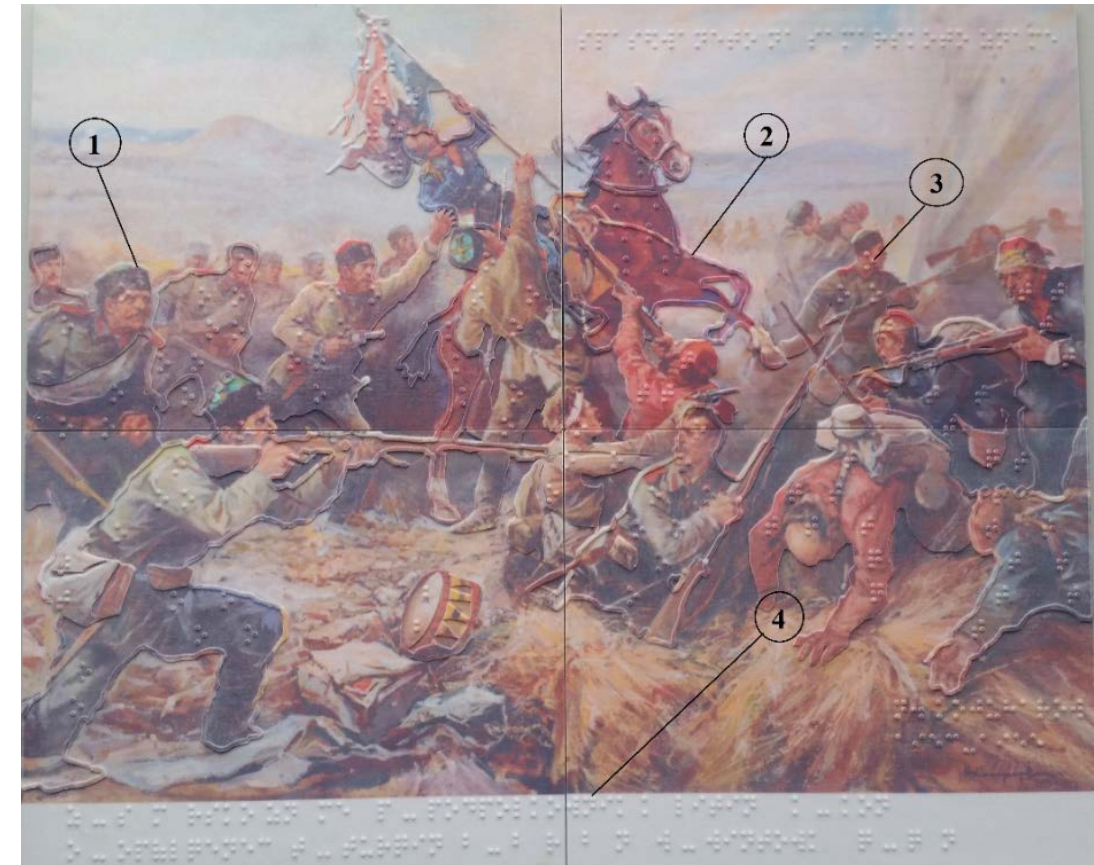

Fig. 3. Tactile tile for visually impaired or blind people.

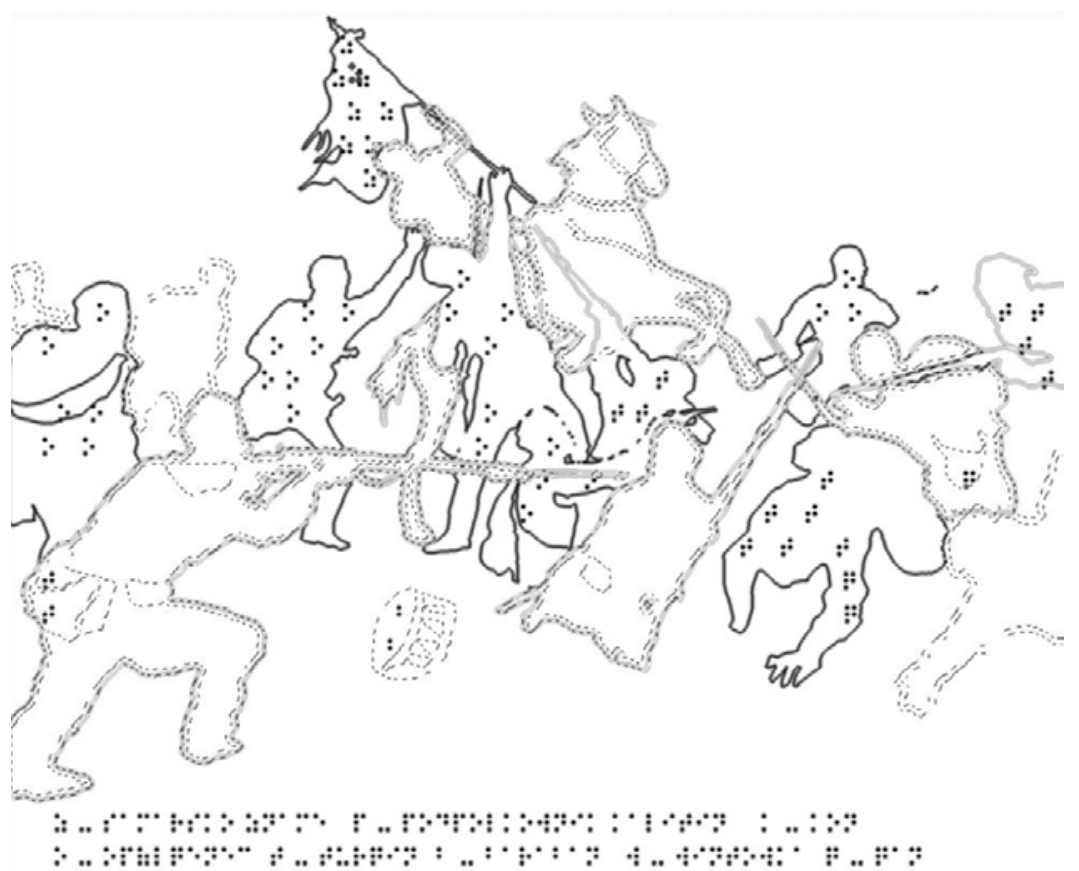

a) Whole tactile tile 


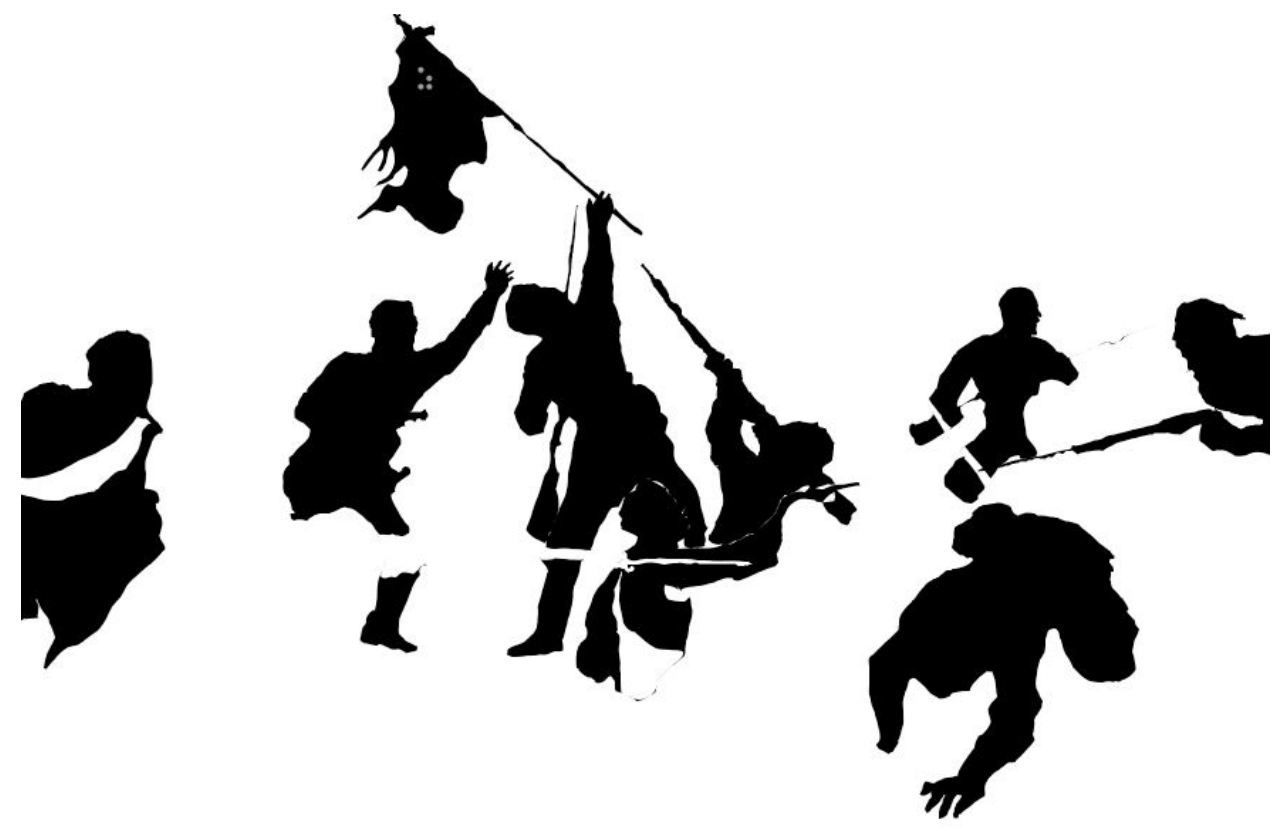

b) Extruded contours

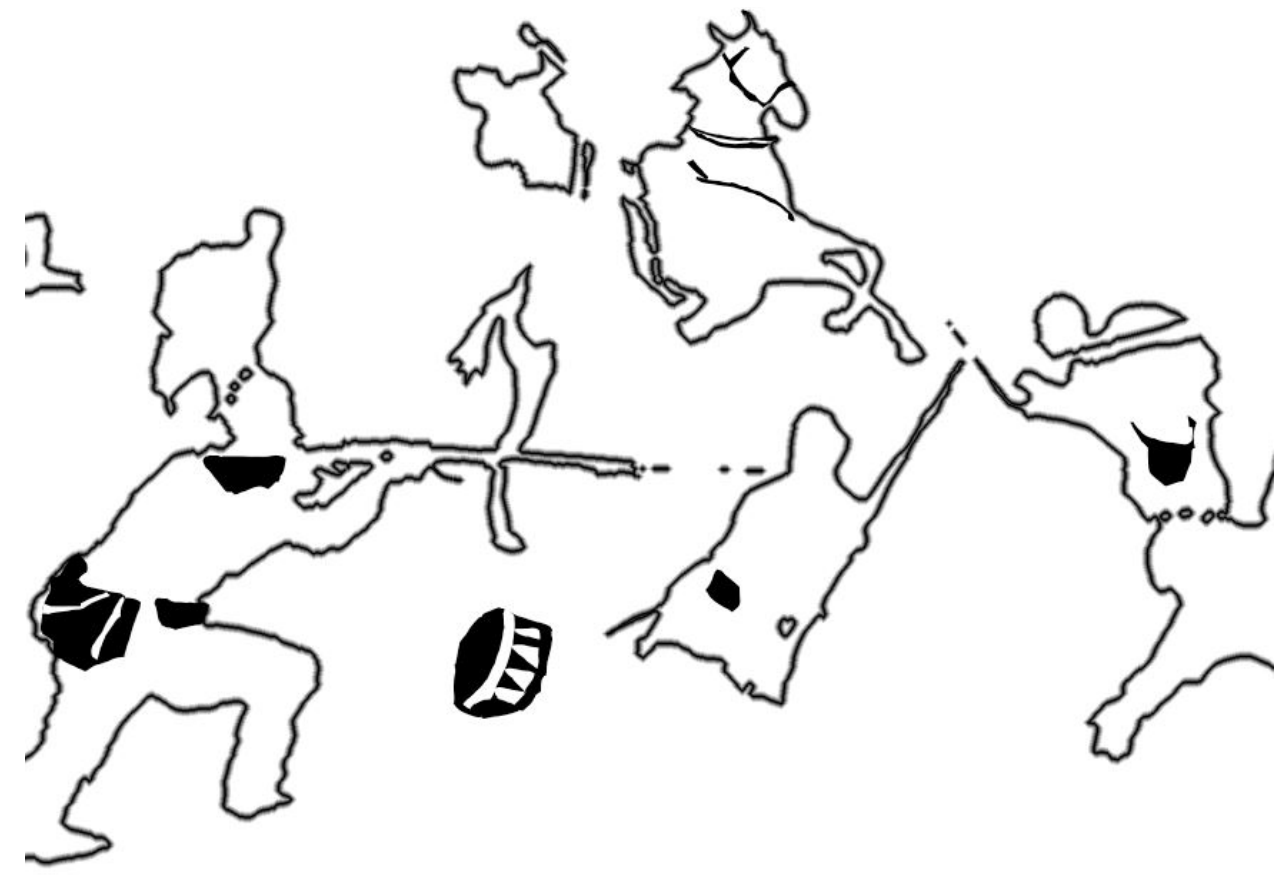

c) Contoured figures

Fig. 4. Details of tactile tile for visually impaired people.
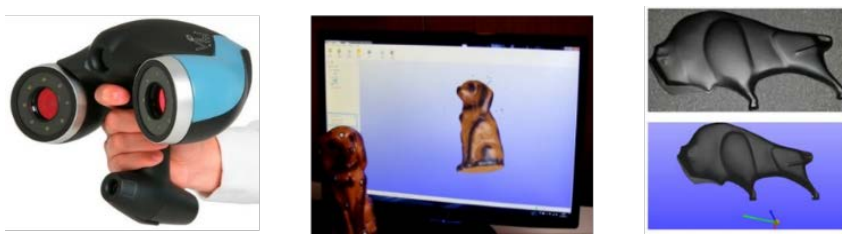

Fig. 5. Using a 3D scanner for digitalizing and printing objects for visually impaired or blind people.

Another method for 3D digitalization is photogrammetry. By using drones and special software, cultural monuments can be $3 \mathrm{D}$ digitalized. That monument can be $3 \mathrm{D}$ printed and presented to those groups of people.

\section{Approaches for Achieving the Goal}

The innovative approach will focus on a synergy using a number of filters which would allow for faster and easier modeling. 3D objects will be modeled from images captured in different artifacts projections.

The collective experience of working with 3D printing materials includes a supply of powder for a VisiJet PLX Core 3D printer as well as a ColorBond infiltrant. For a more durable coating of the $3 \mathrm{D}$ printed paintings, a dual-component infiltrant will be used, allowing for greater strength and durability of the material. This will help to reduce costs and the risk of 
damaging modeling paintings that may be exposed in galleries and museums, which would contribute to improving the quality of life of disadvantaged people.

To reduce the cost of $3 \mathrm{D}$ printing, another $3 \mathrm{D}$ printer working with PLA, ABS will be used. This printer will be used to feedback users to determine the most optimal shape, size, number of detail in paintings, and more. Also, the 3D printed paintings can be used as more budget solutions due to the lower cost of consumables.

\section{Conclusions and Future Developments}

The team aims to achieve the following: fundamental research, resulting in new knowledge and skills in digitization, 3D modeling, processing and 3D printing of objects and paintings of cultural and historical heritage; Use of an innovative approach for digitization, 3D modeling, and 3D printing; Use of different materials for increasing the life and quality of 3D printed objects and paintings of cultural and historical heritage; User feedback; Achieving suitable variants (models), used for representing paintings for visually impaired people.

As future developments, the team aim to digitalize the portraits of national poets, studied in literature lections at schools. The aim is to present them to special schools for visually impaired people. Most of the poets are from the time without color pictures, so for them will be used affordable PLA material.

After digitization and printing of objects, and after the feedback from disadvantaged users, the paintings shapes will be upgraded in order to accomplish a better understanding from the disadvantaged people.

The team also plans to increase the wear resistance and durability of the already used method and materials. Another challenge is to develop the idea and make it more affordable and usable in schools for visually impaired or blind people, not only for museums or exhibitions

Acknowledgment: The paper is partially supported by the BG NSF Grant No KP-06-OPR01/3-2018, and by the National Scientific Program "Information and
Communication Technologies for a Single Digital Market in Science, Education and Security (ICTinSES)", financed by the Ministry of Education and Science.

\section{References}

1. V. Cantoni, D. Karastoyanov, M. Mosconi, A. Setti, (eds.): Pavia, la Battaglia, il Futuro. 1525-2015 Niente fu come prima. CVML e SMART Lab alla Mostra / Pavia, the Battle, the Future. 1525-2015 Nothing was the same again. CVML and SmartLab at the exhibition. Pavia University Press, Pavia (2016)

2. http://www.paviauniversitypress.it/catalogo/paviala-battaglia-il-futuro/371, last accessed 2019/01/07

3. Pinacoteca di Brera. http://pinacotecabrera.org/en/collezioneonline/opere/cristo-e-la-samaritana/ , last accessed 2019/01/07.

4. V. Cantoni, L. Lombardi, A. Setti, S. Gyoshev, D. Karastoyanov, N. Stoimenov, Art Masterpieces Accessibility for Blind and Visually Impaired People. Computers Helping People with Special Needs, 2, 10897, Springer, ISBN:978-3-319-942735, ISSN:0302-9743, pp. 267-274 (2018) DOI:10.1007/978-3-319-94274-2

5. S. Gyoshev, D. Karastoyanov, N. Stoimenov, V. Cantoni, L. Lombardi, A. Setti, Exploiting a Graphical Braille Display for Art Masterpieces. Computers Helping People with Special Needs, 2, 10897, Springer, 2018, ISBN:978-3-319-94273-5, ISSN:0302-9743, pp. 237-245 (2018) DOI:10.1007/978-3-319-94274-2

6. D. Karastoyanov, N. Stoimenov, S. Gyoshev, Tactile graphical tile for visual impaired., BG Patent Application No 112716, March $16^{\text {th }}$ (2018)

7. http://artgallerystz.com/\%D0\%BD $\%$ D0 $\%$ B $8 \% \mathrm{D} 0 \%$ BA $\%$ D0\%BE\%D0\%BB $\%$ D0\%B0$\% \mathrm{D} 0 \% \mathrm{BA} \% \mathrm{D} 0 \% \mathrm{BE} \% \mathrm{D} 0 \% \mathrm{~B} 6 \% \mathrm{D} 1 \% 83 \% \mathrm{D} 1 \% 85 \%$ D0\%B0\%D1\%80\%D0\%BE\%D0\%B2-1892-1971\%D0\%B3/, last accessed 2019/01/07. 